\title{
CORRECTION
}

\section{Correction to: Non-congruent non-degenerate curves with identical signatures}

\author{
Eric Geiger ${ }^{1}$ (D) Irina A. Kogan ${ }^{1}$ (D)
}

Published online: 7 April 2021

๑) Springer Science+Business Media, LLC, part of Springer Nature 2021

\section{Correction to: Journal of Mathematical Imaging and Vision https://doi.org/10.1007/s10851-020-01015-x}

The original version of this article contained a misprint in Eq. 19. It was published without a derivative symbol on $\rho$. The correct equation reads:

$\rho^{\prime}(s)=1$, for all $s \notin \rho^{-1}\left(\Lambda_{1}\right)$

Publisher's Note Springer Nature remains neutral with regard to jurisdictional claims in published maps and institutional affiliations.

The original article can be found online at https://doi.org/10.1007/ s10851-020-01015-x.

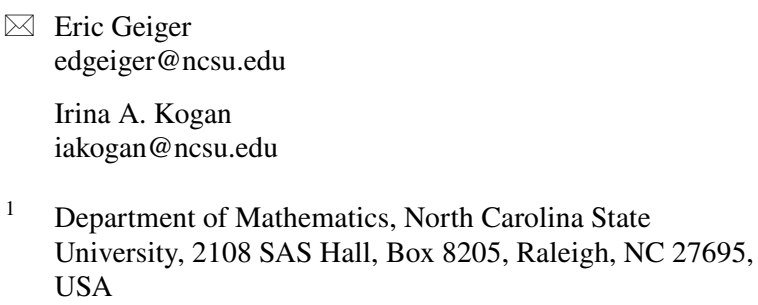

